\title{
Comparing visual acuity in preschool children using the Lea symbols and Sheridan Gardiner charts
}



Visual acuity measurement is a vital part of an optometric examination. The purpose of the present study was to compare visual acuity in preschool children using two charts - the Lea symbols chart and the Sheridan Gardiner chart. One hundred and fifty-three preschool children (72 boys and 81 girls) between the ages of 3 and 5 years (mean age and standard deviation $4.23 \pm 0.78$ years) were recruited from five randomly selected nursery schools. Distance visual acuity was measured monocularly and binocularly after a pre-test was done. An interval of 5 minutes was allowed for testing with both charts. The ages and sexes of each child were documented. Results showed a statistical difference in visual acuities using both charts $(p<0.05)$. There was also a statistical difference in both charts regarding age. There was no significant gender difference between the results from each chart.

\section{Introduction}

Vision is the appreciation of differences in the external world, such as form, colour and position, resulting from stimulation of the retina by light, whilst acuity is the capacity for seeing distinctly the details of an object. ${ }^{1}$ Visual acuity (VA) is the resolving power of the eye or the ability to see two separate objects as separate. The normal eye can resolve two objects as separate ${ }^{2}$ (with adequate illumination and contrast) if they are separated by an angular distance of one minute of arc. VA is the spatial resolving capacity of the visual system and expresses the angular size detail that can just be resolved by a person. ${ }^{3}$

Measurement of visual acuity can be done by detection acuity, resolution acuity or recognition acuity. Detection acuity is the ability to detect the presence or absence of a specific target such as a dot, symbol or grating. Resolution acuity is the ability to resolve the critical element of a stimulus pattern such as the orientation of the gap in a Landolt $C$ optotype or the direction of the limbs in a Tumbling E. ${ }^{4,5}$ Recognition acuity is the ability to identify a particular object. Most clinical tests of VA are recognition tests. Recognition acuity is determined by the smallest optotype that can be identified by the observer. Optotypes can be letters, numbers or symbols. ${ }^{3}$ There are several notations by which VA can be represented. They include the Snellen fraction, decimal notation, minimum angle of resolution (MAR) and logarithm of minimum angle of resolution (logMAR). As for distance VA, near VA is also specified by the observation distance and the size of the smallest print that can be read. Several notations can be used including $\mathrm{M}$ or $\mathrm{N}$ notation, reduced Snellen notation, and point or Jaeger notation.

Measurement of VA is a crucial part in any ocular health assessment whether in children or adults, and perhaps remains the most frequently used technique for assessment of vision. VA is a clinical test that gives insight into the child's visual status. Measurements of VA are most especially important in children as the procedure not only detects ametropia and pathology but also detects binocular problems such as amblyopia. VA can be measured in infants and toddlers using behavioural and electrophysiological techniques (such as preferential looking tests, optokinetic nystagmus and visually evoked potential tests). For preschool children, VA can be measured using acuity charts, which are either picture/symbol tests or letter acuity tests. Picture/symbol tests require the child to match or name familiar pictures/symbols that are presented to him/her. The same principle applies to letter charts but with letters of the alphabet making up the chart.

The Sheridan Gardiner test chart is a development of the Stycar letter charts by Drs Sheridan and Gardiner; hence the name of Sheridan Gardiner chart. ${ }^{6}$ The chart is composed of seven vertically symmetrical and easily recognisable letters $(\mathrm{H}, \mathrm{U}, \mathrm{X}, \mathrm{T}, \mathrm{A}, \mathrm{V}$ and $\mathrm{O})$. The distance chart is in the form of a spiral bound booklet with one letter on each page and is designed for a test distance of either $6 \mathrm{~m}$, or $3 \mathrm{~m}$ with a mirror. The child is to match the letter on the chart on his key card. The Sheridan Gardiner chart also has a near card for near vision testing and is of two forms: the reduced Snellen and reduced Roman type. This test is suitable for preschool children because, 
although they may not be able to name the letters, they can match them.

The Lea symbol chart is designed for children who do not know how to read the letters of the alphabet that are typically used in vision charts. It was first developed in 1976 by Lea Hyvarinen, a Finnish paediatric ophthalmologist, and consists of four symbols: a circle, square, apple and house which have now been calibrated against the Landolt $C$ chart as required by the International Commission for Optics (ICO) standard. The design of the Lea symbols eliminates any directionality confusion. The chart is available in many different formats so that children can be tested at distant and near, $\log$ MAR or non-logMAR presentations. There are verbal or matching (nonverbal) testing response formats, isolated, whole line, whole chart (folding or nonfolding) and surrounded (crowding effect) optotypes. ${ }^{7}$ These formats offer the clinician many different ways of obtaining clinical data on children.

The present study compared VA results in children using the Sheridan Gardiner chart and the Lea symbol chart.

\section{Methodology}

The purpose of the study was to determine whether there was a difference in preschool children in VA measurements between the Lea symbol chart and the Sheridan Gardiner chart. The sample included children aged 3 to 5 years old in nursery schools in Benin City, Edo State, Nigeria. Their mean age and s.d. were $4.23 \pm 0.78$ years. The sample size was 153 children comprising 81 girls and 72 boys from 5 randomly selected nursery schools in Benin City. The study was carried out over a period of 2 months.

Before commencement of the study, consent was obtained from the parents/guardians of the children and the schools. Ethical approval was also received from the Department of Optometry, University of Benin Ethics Committee.

Children who could not identify the symbols/letters of the charts during the pre-test, and children whose consent forms were not signed by their parents/guardians, were excluded from the study. The test was done in a bright, airy classroom, free of distractions. Lea symbols distance and near charts and Lea symbols response key cards were used as well as Sheridan Gardiner distance and near charts and Sheridan Gardiner response key cards.

\section{Pre-test}

First, it was ascertained whether the child could identify the symbols/letters on the various charts. The child was given a key card with the appropriate group of symbols - either the four pictures used in the Lea symbols chart or the seven letters used in the Sheridan Gardiner chart. A card with a single large symbol (or letter if the Sheridan Gardiner was the chart to be tested) was held at $60 \mathrm{~cm}$ from the child, and the child asked to point to the symbol or letter on his/ her card that was similar to that in front of him/her. This procedure was repeated for the remaining three symbols (or six letters). No more than two chances to respond correctly to each of the cards were allowed, and only those children who responded correctly to all the cards were accepted into the study. If the child spontaneously named the letters or pictures, verbal responses were accepted. ${ }^{8}$ Children who did not pass the pre-test were excluded from the study.

\section{Distance Visual acuity testing procedure}

After the child had passed the pre-testing session, VA assessment at distance was immediately performed. The child's distance VA was tested monocularly and then binocularly using both charts. The right eye was always tested first and the left eye next. The sequence of charts tested was randomised.

The Lea symbols chart was presented at 3 metres in front of the child, and the child asked to identify the first letters on each line by pointing to the symbol on the key card similar to that shown to her/him until the child missed an optotype. At this point, the child was directed to the previous line and asked to identify all the optotypes of that line. If the child was able to identify all the optotypes on that line, the child then continued on to the next line, identifying all optotypes. If not, the next largest level was shown to the child and optotypeby-optotype scoring was used.

The booklet format of the Sheridan Gardiner chart was presented at 6 metres in front of the child. Each page is flipped, revealing a letter. The child was asked to identify each letter by pointing to the letter similar to that in front of her/him on the key card. VA was recorded as the smallest letter that the child could identify. The $\log$ MAR notations were employed, from which the VA scores were derived. The VAs and the age and sex of the child were recorded.

\section{Data analysis}

Data analyses were performed using SPSS version 21. The paired $t$-test was used to compare the results of both charts. The unpaired Student $t$-test was used to compare the results from the boys and girls. One-way analysis of variance (ANOVA) and post hoc tests to compare the results of the different age groups were also performed

\section{Results}

A total of 153 children participated in the study comprising 72 boys and 81 girls. Just over $44.4 \%$ of the participants were 5 years old, $34 \%$ were 4 years old, and $21.6 \%$ were 3 years old. The mean age for the children was $4.23 \pm 0.78$ years.

The figures in Table 1 show that there was a statistical difference in the results from the various age groups $(p<0.05)$ and the difference arose mainly amongst the 3-yearolds. Means are statistically significant at a $95 \%$ confidence interval. 
TABLE 1: Comparing the mean visual acuity scores (in logMAR) across the three different age groups using both charts.

\begin{tabular}{llcccc}
\hline VA chart & Eye tested & $\mathbf{3}$ years & $\mathbf{4}$ years & $\mathbf{5}$ years & $\boldsymbol{p}$-value \\
\hline Lea symbols & OD & $0.38 \pm 0.09^{\mathrm{a}}$ & $0.25 \pm 0.13^{\mathrm{b}}$ & $0.18 \pm 0.19^{\mathrm{b}}$ & 0 \\
& OS & $0.38 \pm 0.08^{\mathrm{a}}$ & $0.24 \pm 0.10^{\mathrm{b}}$ & $0.20 \pm 0.19^{\mathrm{b}}$ & 0 \\
& OU & $0.32 \pm 0.08^{\mathrm{a}}$ & $0.21 \pm 0.13^{\mathrm{b}}$ & $0.16 \pm 0.18^{\mathrm{b}}$ & 0 \\
Sheridan & OD & $0.14 \pm 0.14^{\mathrm{a}}$ & $0.07 \pm 0.14^{\mathrm{b}}$ & $0.04 \pm 0.10^{\mathrm{b}}$ & 0.001 \\
Gardiner & OS & $0.13 \pm 0.11^{\mathrm{a}}$ & $0.05 \pm 0.12^{\mathrm{b}}$ & $0.03 \pm 0.09^{\mathrm{b}}$ & 0 \\
& OU & $0.07 \pm 0.10^{\mathrm{a}}$ & $0.03 \pm 0.07^{\mathrm{b}}$ & $0.02 \pm 0.06^{\mathrm{b}}$ & 0.002 \\
\hline
\end{tabular}

VA, Visual acuity; OD, right eye; OS, left eye; OU, both eyes.

$\mathrm{a}, \mathrm{b}$, the mean visual acuity scores with different superscript is statistically significant at $95^{\circ}$ confidence interval.

TABLE 2: Comparing the performance of boys and girls with both charts.

\begin{tabular}{llccc}
\hline VA chart & Eye tested & Boys & Girls & $p$-value \\
\hline Lea symbols & OD & $0.24 \pm 0.21$ & $0.25 \pm 0.13$ & 0.714 \\
& OS & $0.23 \pm 0.20$ & $0.27 \pm 0.12$ & 0.139 \\
& OU & $0.19 \pm 0.19$ & $0.23 \pm 0.13$ & 0.159 \\
Sheridan Gardiner & OD & $0.06 \pm 0.12$ & $0.09 \pm 0.13$ & 0.213 \\
& OS & $0.05 \pm 0.10$ & $0.07 \pm 0.12$ & 0.471 \\
& OU & $0.03 \pm 0.07$ & $0.04 \pm 0.08$ & 0.252 \\
\hline
\end{tabular}

VA, Visual acuity; OD, right eye; OS, left eye; OU, both eyes.

Note: Units are logMAR.

Table 2 shows the mean VA scores and SD of the boys and girls using both charts. There were no statistically significant differences in the results $(p>0.05)$.

\section{Discussion}

The purpose of the present research was to determine whether there were significant differences in the distance VA results from the Lea symbols chart and the Sheridan Gardiner chart in preschool children. The results obtained showed a statistically significant difference in the results of both charts $(p<0.05)$. The mean VA for the Lea symbols chart was larger than that for the Sheridan Gardiner, both monocularly and binocularly. This finding is in line with a similar study conducted by other workers, ${ }^{9,10}$ where they found a significant difference in the two charts compared. The difference could be attributed to the crowding effect, single letters and grading scales, and the VA scoring technique. The Sheridan Gardiner chart lacks contour effect, uses single letters, and uses a $0.20 \mathrm{log}$ unit scale for every change in the unit, as against the Lea chart that has consistent scale increments that provide a finer range of $0.10 \log$ unit differences, and has a crowding effect and uniform optotypes per line. This explanation holds true for the present study also. Results from other studies have found that the Sheridan Gardiner chart tends to over-exaggerate VA scores. ${ }^{10,11}$ This tendency is seen in the present study in the lower mean VA scores, which indicates better VA. The present research, however, differs from that by other authors, where no statistical difference was found between the Lea symbols chart and the HOTV chart. $12,13,14,15$

There was a significant difference between both charts regarding the different age groups $(p<0.05)$, as revealed using the one-way ANOVA test. Post hoc tests revealed the difference arising from the 3-year-old group, which probably can be attributed to the developmental level and shorter attention span of this age group.

We therefore recommend that clinicians perform vision screening with appropriate acuity charts for children, to help early detection of amblyopia and vision impairment.

\section{Conclusion}

In the present study, we found the Lea symbols chart to be more reliable in VA testing than the Sheridan Gardiner chart, especially in the 3-year-old group studied.

\section{Acknowledgements Competing interests}

The authors declare that they have no financial or personal relationships which may have inappropriately influenced them in writing this article.

\section{Authors' contributions}

A.B.O. (University Of Benin) was the project leader. She did the experimental and project design. G.N.A. (University Of Benin) organised samples and calculations as well as conceptual contributions.

\section{References}

1. Millodot M. Dictionary of optometry and visual science. 7th edn. Missouri: Butterworth; 2009

2. Grosvenor T. Primary care optometry. Preliminary examination. 5th edn. Missouri: Butterworth, 2007; pp. 112-116.

3. Bailey IL. Visual acuity. In: Benjamin WJ, editor. Borish's clinical refraction. 2nd edn. Missouri: Butterworth, 2006; pp. 217-244. http://dx.doi.org/10.1016/B9780-7506-7524-6.50012-0

4. Lay $M$, Wickware $E$, Rosenfield M. Visual acuity and contrast sensitivity. In: Rosenfield M, Logan N, Edwards K, editors. Optometry: Science, techniques and clinical management. 2nd edn. Missouri: Butterworth, 2009; pp. 173-178.

5. Jackson AJ, Bailey IL. Visual acuity. Optom Pract. 2004;5:53-70.

6. Sheridan MD, Gardiner PA. Sheridan Gardiner test for visual acuity. Br Med J. 1970;2:108-109. http://dx.doi.org/10.1136/bmj.2.5701.108

7. Duckman RH. Visual development, diagnosis and treatment of the paediatric patient. In: Duckman RH (ed.) Infant, toddler, and children's visual acuity practical aspects. Philadelphia, PA: Lippincott, 2006; p. 480.

8. McGraw PV, Winn B. Measurement of letter acuity in preschool children. Ophthal Physiol Opt. 1995;15:11-17. http://dx.doi.org/10.1046/j.1475-1313.1995. 0150s1S11.x

9. Omar R, Hussin DA, Knight VF. Comparison of Lea symbols chart and Sheridan Gardiner chart in assessing vision screening among preschool children: A Malaysia perspective. J Med Thai. 2012;95:412-417.

10. Simmers AJ, Gray LS, Spowart K. Screening for amblyopia: A comparison of paediatric letter tests. Br J Ophthalmol. 1997;81:465-469. http://dx.doi.org/ 10.1136/bjo.81.6.465

11. Schlenker MB, Christakis TJ, Braga-Mele RM. Comparing a traditional single optotype visual acuity test with a computer based visual acuity test for childhood amblyopia vision screening: A pilot study. Can J Ophthalmol. 2010;45:368-374. http://dx.doi.org/10.3129/i10-034

12. Hered RW, Murphy S, Clancy M. Comparison of the HOTV and Lea symbols chart for preschool vision screening. J Paediatr Ophthalmol Strabismus. 1997;34:24-28.

13. Kvarnstrom G, Jakobsson P. Is vision screening in 3-year-old children feasible? Comparison between the Lea symbol chart and the HVOT (LM) chart. Acta
Ophthalmol Scand. 2005;83:76-80. http://dx.doi.org/10.1111/j.1600-0420.2005. Ophthalmol
00367.x

14. Cyert L, Schmidt P, Maguire M, Moore B, Dobson V, Quinn G. Vision in pre-schoolers study group. Threshold visual acuity testing of preschool children pre-schoolers study group. Threshold visual acuity testing of preschool children
using the crowded HOTV and Lea symbols acuity tests. J AAPOS. 2003;7:396-399. using the crowded HOTV and Lea symbols acuity tests.
http:/dx.doi.org/10.1016/S1091-8531(03)00211-8

15. Vision in pre-schoolers study group. Preschool visual acuity screening with HOTV and Lea symbols: Testability and between-test agreement. Optom Vis Sci. 2004;81:678-683. http://dx.doi.org/10.1097/01.opx.0000144746.80718.67 